Original article

\title{
Impact of lockdown on self-care management among patients with type 2 Diabetes Mellitus residing in Lucknow city, India - A cross-sectional study
}

\author{
Ajoy Tiwari ${ }^{a}$, Dinesh Kumar ${ }^{\mathrm{a}}$, Mohammad S. Ansari ${ }^{\mathrm{b}}$, Santosh Kumar Chaubey ${ }^{\mathrm{c}}$, \\ Nitin R. Gupta ${ }^{\text {a,d }}$, Vivek Agarwal ${ }^{\mathrm{e}}$, Kumar Prafull Chandra ${ }^{\mathrm{a}}$, Arunkumar r Pande ${ }^{\mathrm{a}, \mathrm{c}, *}$, \\ Rajiv Awasthi ${ }^{a}$, Mukulesh Gupta ${ }^{a}$, Sandeep Chowdhary ${ }^{f}$ \\ a Diabetologist and Private Practitioner, Lucknow, Uttar Pradesh, India \\ ${ }^{\mathrm{b}}$ Clinical / Non-Invasive Cardiologist, S. S. Heart Care Center, Lucknow, Uttar Pradesh, India

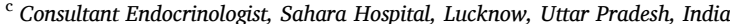 \\ d Consultant Endocrinologist, Lucknow Hormone Center, Lucknow, Uttar Pradesh, India \\ ${ }^{\text {e }}$ Consultant Physician, R. R. Diabetes and Heart Care Center, Lucknow, Uttar Pradesh, India \\ ${ }^{\mathrm{f}}$ Senior Consultant Physician, Department of Medicine, Ram Manohar Lohiya Institute of Medical Sciences, Lucknow, Uttar Pradesh, India
}

\section{A R T I C L E I N F O}

\section{Keywords:}

COVID-19

Diabetes mellitus

Self-management

Self-monitoring of blood glucose

Stress

\begin{abstract}
A B S T R A C T
Objective: To assess the effect of nationwide lockdown and its associated repercussion on the self-care management of Type 2 Diabetes Mellitus (T2D).

Methods: Response from 1406 diabetic patients was collected against a 16 item questionnaire. Data was collected on diabetic self-management practices, behavioral aspects, psychological implications, drug availability and awareness towards the pandemic. Emphasis was on choices made by patients in the absence of guidance from physicians and impact of stress and blood sugar levels on other variables. The data was analyzed using Chi-square tests at $\mathrm{P}<0.05$.

Results: About 27\% were under stress, $14.7 \%$ and $30.8 \%$ reported a change in dietary and sleep pattern. About $83 \%$ could not consult a doctor and as a result 13\% stopped taking medications. Patients with stress slept less, observed a change in dietary patterns and had uncontrolled blood sugar levels $(\mathrm{P}=0.0001)$. On the contrary those without stress spent time with family and were occupied with a hobby $(\mathrm{P}=0.0001)$. Those with controlled blood sugar levels exercised more and had normal sleep patterns. Fluctuation with doses was observed among those with uncontrolled blood sugar levels in the absence of physicians consultation $(\mathrm{P}=0.001)$.

Conclusion: Even though majority of study participants were not able to consult their physicians yet nearly $2 / 3$ rd were practicing Self-Monitoring of Blood Glucose (SMBG), more than half were exercising regularly, more than $2 / 3^{\text {rds }}$ continued taking their medications and majority were following appropriate diet pattern. Stress management is a key factor during these times due to its association with other variables.
\end{abstract}

\section{Introduction}

With the advent of Corona pandemic, several countries including India announced complete lockdown in an attempt to contain the spread of Corona Virus Disease (COVID-19). With growing research it became evident that the elderly and those with additional co-morbidities in the form of diabetes, hypertension and cardiovascular disorders are associated with a poorer prognosis. ${ }^{1}$

According to World Health Organization (WHO) about 422 million people worldwide have diabetes ${ }^{2}$ and it is a growing challenge in India with an estimated prevalence of $8.9 \%$ between the age group of 20 and 70 years. $^{3}$ As of 2019, India had about 77 million people with diabetes [with Type 2 Diabetes Mellitus (T2D) accounting for $90 \%$ of the total]. ${ }^{4}$ The current pandemic has brought about unprecedented repercussions on social, economic and psychological fronts. These are directly or indirectly related to measures adopted to prevent the transmission of COVID-19. People had no option but to remain indoors thereby resulting in limitation of free space to exercise, difficulty in maintaining healthy

\footnotetext{
* Corresponding author. DM (Endocrinology) Endocrinologist Sahara Hospital and Lucknow Endocrine Diabetes and Thyroid Clinic 2/1, Vivek Khand, Gomti Nagar Lucknow - 226010 Uttar Pradesh, India.

E-mail address: drarunendocrine@gmail.com (A. Pande).
} 
lifestyle and in obtaining doctors' guidance. These can have profound effect on control of blood sugar levels in people living with Diabetes. In addition, lack of mobility and un-availability of diabetes care supplies, behavioral aspects and attitudes of patients resulting from limited options and lack of usual standards of care could adversely affect diabetes care and subsequent increase in complications. However, more family time, time to relax and introspect, redefining health goals and more time to exercise may also lead to positive outcomes.

It is also worrisome for healthcare providers since patients with COVID-19 with diabetes exhibit a worse prognosis, most probably because of the concurring effect of multiple factors. ${ }^{5}$ Many studies conducted in different parts of the world have reported the association of diabetes with increased Intensive Care Units [ICU] admissions, higher mortality due to COVID-19 (with diabetes) and a relatively higher prevalence of diabetes among those who died due to COVID-19. ${ }^{6-10}$ Therefore, following recommended diabetes control measures during challenging times is of paramount importance.

Patient empowerment and self-management skills are of utmost importance in chronic disease care model. These must continue outside the clinical care system, beyond the community and at homes. The lockdown phase provided us with a window of opportunity to assess patients' ability in managing their own diabetic needs. The present study was conducted to observe any changes in lifestyle, self-care practices, psychological aspects and health-care seeking behavior among patients with T2D during lockdown.

\section{Methodology}

\subsection{Study design and setting}

A multi-center, cross-sectional, questionnaire study was conducted to determine the impact of lockdown on patients with T2D who reported to various clinics in the city of Lucknow, Uttar Pradesh, India, in the month of June 2020.

\subsection{Study participants}

With an acceptable error of 5\%, 95\% confidence interval, desired precision at $4 \%$ ( 2 tailed) and power of $80 \%$, the estimated sample size was 1224 . With an anticipated non-response rate of $10 \%$, the final sample size was 1346 . All patients with T2D routinely visiting various clinical centers in the month of June after lockdown due to COVID-19 formed the target population and was screened for eligibility. The study adhered to the principles of Declaration of Helsinki. ${ }^{11}$ Patients' $\geq$ 18 years of age with T2D receiving medications at a particular center for $\geq$ six months were included. The nature of the study was verbally explained to patient and only after informed verbal consent was obtained, they were included in the study as participants. Patients' $\leq 18$ years of age, suspected or confirmed pregnancy or unable to comply with protocol requirements (completion of questionnaire and not providing the consent) were excluded from the study. Confidentiality and anonymity of their responses were assured and the participants were not given any incentives to be a part of the study and could withdraw from the study at any time. Patients who consecutively reported to centers were selected till the desired sample size was achieved.

\subsection{Study instrument}

A closed ended, 16 item structured questionnaire was used to elicit responses from patients. The questionnaire was framed in regional language (Hindi). Given the pandemic, all precautions were followed and data was collected through face-to-face interview using an interviewer-administered method. The data was collected from study participants on their first visit after lockdown. Data included responses to subjective questions regarding behavioral aspects (e.g., changes in dietary pattern, utilization of leisure time, attitude in the absence of their physician, etc.), self-care practices (e.g., monitoring blood sugar level, regular exercise, attempt to contact doctors for guidance etc.) and the psychological implications (perception of stress and patterns of sleep) experienced during lockdown. Patients with blood sugar level in the range of $80-130 \mathrm{mg} / \mathrm{dL}$ (pre-meals) and $<180 \mathrm{mg} / \mathrm{dL}$ (post meals) were considered as controlled blood sugar level. Anything more than the above mentioned values were considered as patient with un-controlled blood sugar level. If at all, patients chose to discontinue their regular dose of medication, an attempt was made to draw reasons for the same. We also tried to gauge patients' understanding regarding the Corona pandemic, its gravity in the setting of diabetes and precautionary measures taken by them. Completed questionnaires were collected by the investigators. Incomplete questionnaires if at all were not included in statistical analysis.

\subsection{Statistical analysis}

The data was entered in Microsoft Excel sheet [MS Office 2013, Microsoft Corp] and was analyzed using Statistical Package for Social Sciences [SPSS ver 22.0 Armonk, NY, IBM Corp]. The data was analyzed for descriptive statistics and presented using graphs and tables. Variables of interest were cross tabulated to observe any statistical significance using Chi-Square test. The level of significance was set at $\mathrm{P}<0.05$.

\section{Results}

A total of 1406 study participants consented to be a part of the study. The collected data exceeded from the calculated sample size of 1346 . It was found that about $83 \%(1171 / 1406)$ could not consult their treating physician, $54.27 \%(763 / 1406)$ regularly exercised during lockdown, about $27 \%$ (380/1406) were reportedly under stress and 81.22\% (1142/ 1406) did not face any difficulty in procuring anti-diabetic medicines. (Graph 1) About 69.7\% (980/1406) of study participants monitored their blood sugar levels, 65\% (642/980) monitored their blood sugar levels at least 1 to 5 times and $60.61 \%(594 / 980)$ had their blood sugar levels under control (Table 1). Among those who could not monitor their blood sugar levels $(\mathrm{N}=426)$, not possessing a glucometer $(191 / 426)$ and not feeling the need to monitor their blood sugar levels $(136 / 426)$ were most common reasons cited by study participants. In addition, majority of study participants felt good to spend a lot of time with their family during lockdown, kept themselves occupied with a hobby and were knew preventive measures to be followed during COVID-19 (Table 1).

Among those who could not consult their treating physicians (1171/ 1406), about $82 \%(960 / 1171)$ opted to continue their medication as prescribed earlier and $13 \%(152 / 1171)$ stopped their medications. (Graph 2) Reasons like 'medical stores were closed', 'doubt in the dose of medicines/had other medical conditions' and 'financial difficulties (since no job)' were cited for the same (Table 2).

Variables like feeling good to spend more time with family, keeping oneself occupied with a hobby, normal dietary and sleep patterns, controlled blood sugar levels were significantly associated with study participants who were not under perceived stress $(P=0.0001)$. However, it was also found that a significant proportion of participants under stress slept less and a small proportion of study participants had difficulty in procuring anti-diabetic medicines $(P=0.0001)$ (Table 3$)$. A significant association between controlled T2D with exercise $(P=$ $0.001)$, patient practices in absence of physicians' guidance $(P=0.001)$ and sleeping pattern $(P=0.0001)$ was also observed (Table 4$)$.

\section{Discussion}

COVID-19 has emerged as a global pandemic affecting millions of people worldwide and claiming thousands of lives till date. A nationwide lockdown was initiated as a preventive measure to break the chain in spread of infection. This has resulted in a gradual shift from physician- 


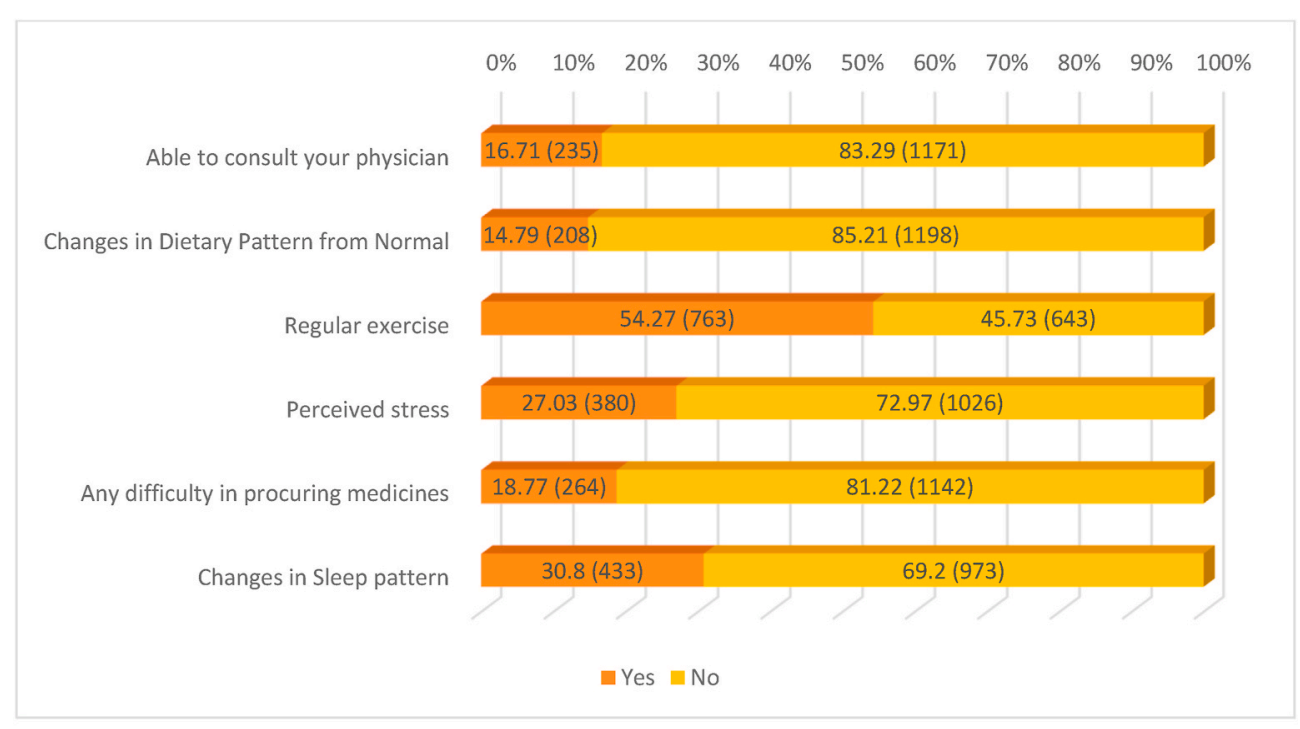

\section{$\%$ - Percentage; $\mathrm{N}$ - Frequency}

Graph 1. Daily self-care activities during lockdown due to COVID-19 [\% (N)]

Table 1

Study participant's responses on their self-care practices and awareness on COVID-19.

\begin{tabular}{ll}
\hline Variables & $\%(\mathrm{~N})$ \\
\hline Self-monitoring of blood glucose & $69.7(980)$ \\
$\quad$ Yes & $30.3(426)$ \\
$\quad$ No & \\
Reasons for not monitoring blood sugar $(\mathrm{N}=426)$ & $44.8(191)$ \\
$\quad$ No glucometer & $13.38(57)$ \\
$\quad$ Glucometer strips got over Did not feel the need to check & $31.9(136)$ \\
$\quad$ No response & $9.86(42)$ \\
Frequency of checking sugar levels $(\mathrm{N}=980)$ & \\
1 to 5 times & $65.5(642)$ \\
more than 5 times & $34.5(338)$ \\
Sugar levels when checked the last time (N =980) & \\
Under Control & $60.61(594)$ \\
Not under Control & $39.39(386)$ \\
Study participants perspective during lockdown (N $=1406)$ & $9.46(133)$ \\
$\quad$ A lot of physical, mental and financial difficulties & $29.3(412)$ \\
$\quad$ Given circumstances, it was difficult & $61.23(861)$ \\
$\quad$ Good to spend a lot of time with family & \\
How did you spend your time during lockdown & $12.66(178)$ \\
$\quad$ Slept a lot & $53.13(747)$ \\
Busy with a hobby & $23.97(337)$ \\
Watched excessive Television & $10.24(144)$ \\
Could not stay at home due to work & $87.84(1235)$ \\
Effect of Corona disease on other co-morbidities & $12.16(171)$ \\
$\quad$ Yes & \\
$\quad$ No & $88.05(1238)$ \\
Preventive measures taken during lockdown & $11.16(157)$ \\
$\quad$ Partial Precautions & $0.78(11)$ \\
$\quad$ Did nothing & \\
\hline
\end{tabular}

$\%$ - Percentage; N - Frequency.

centered approach to patient-centered approach with more focus on selfcare practices among diabetic population.

There is a growing acknowledgment of sustaining a multitude of daily self-management decisions by T2D patients. This includes SMBG, adherence to medication, physical activity, diet and psychological issues applicable in an Indian setting. ${ }^{12,13} \mathrm{An}$ important component of self-care management practice for diabetics is SMBG, which was followed by about $69 \%$ of patients. This was similar to a study conducted in South India where $71 \%$ of patients (28\%: regularly and $43 \%$ : sometimes) adhered to SMBG procedure. ${ }^{14}$ Nevertheless, unavailability of glucose strips, not possessing glucometer and lack of perceived need to monitor their blood sugar levels were some of the reasons reported by patients who did not monitor their blood sugar levels. This highlights a section of T2D patients (do not possess a glucometer due to various reasons) who were still dependent on physician centered care even to monitor their blood sugar levels. We attribute this finding to lack of knowledge among patients.

The lockdown amid COVID-19 pandemic has created an array of challenges for diabetes self-management, forcing people to stay indoors resulting in restricted physical activities, restriction in food supplies, unavailability of anti-diabetic medications and inability to meet their treating physicians. Nevertheless, it was note-worthy that about $54.27 \%$ of T2D patients were regularly exercising and majority of patients did not observe any major change in their dietary pattern indicating a good compliance with self-care behavior. ${ }^{13}$ We also observed that, $65.5 \%$ of T2D patients checked their blood sugar level 1 to 5 times and $60.61 \%$ reportedly had their blood sugar level under control.

A small proportion of T2D patients had difficulty in procuring medicines and because of home confinement, a relatively large proportion (1171/1406) of T2D were unable to contact their treating physicians. On further analysis we found that majority of patients (960/ 1171) took their medicines as prescribed that was similar to results available in literature albeit not during a pandemic. ${ }^{15,16}$ In addition, $13 \%(152 / 1171)$ had stopped taking their medicines due to various reasons reflecting a poor adherence to medication. However, those who stopped taking medication revealed that closure of medical stores, doubt in the dose of medicines/other medical ailments, financial difficulties (since no job) and fear of contracting corona virus disease were some of the major reasons for discontinuing their medication during lockdown.

Research has shown a relationship between diabetes and mental health issues that can aggravate under stressful situations. In the wake of COVID-19 and related limitations, there is a possibility of psychological distress and subsequent refusal to initiate insulin therapy among diabetic population under certain conditions. ${ }^{17}$ Therefore, stress and negative emotions can have an impact on glycemic levels as a response towards a new change in life. ${ }^{18}$ As a result of the new emerging change, we observed that T2D patients who were free from stress also had controlled blood sugar levels. It was also observed that, $61.24 \%$ of T2D patients felt good by spending lot of time with their families and over $50 \%$ involved themselves in a new hobby to spend most of their time during lockdown. Since family is a fundamental unit of any society in 


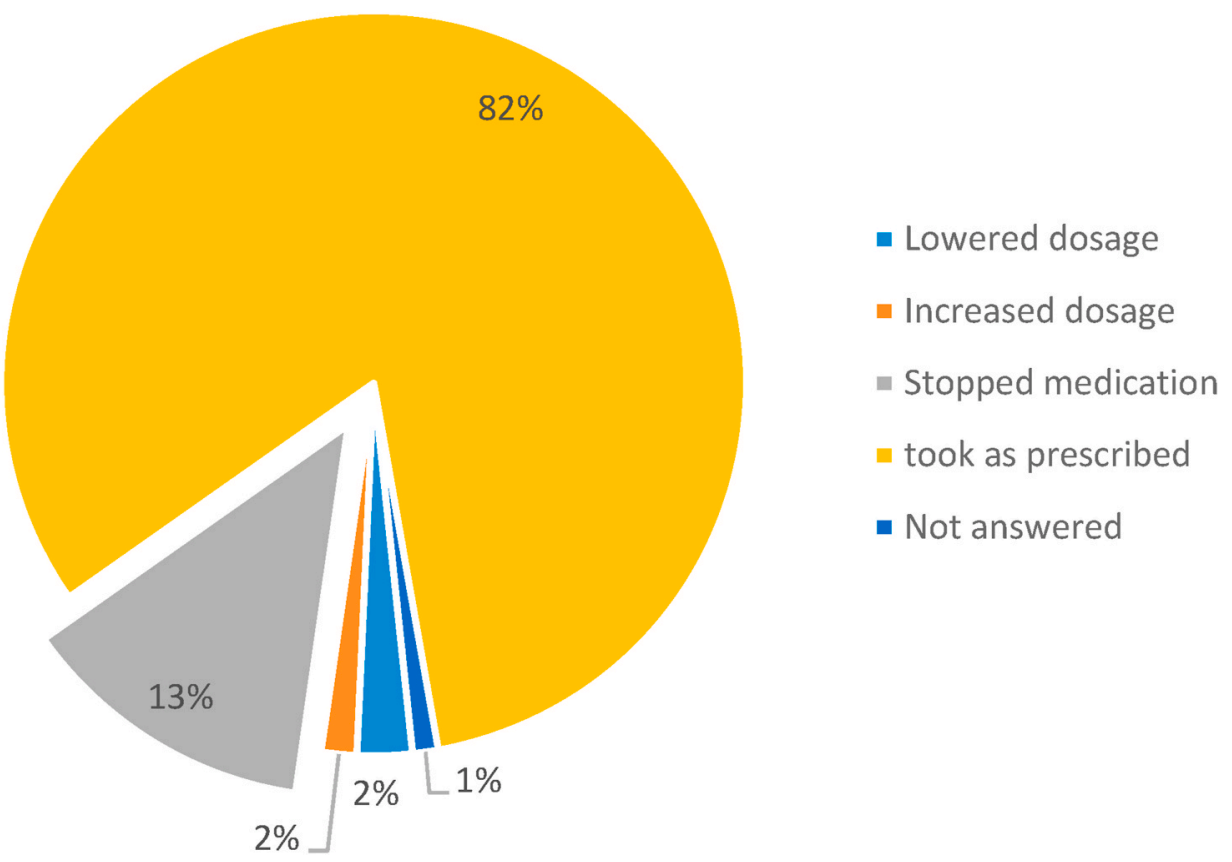

Graph 2. Steps taken by study participants' who could not consult their treating physicians

Table 2

Reasons for stopping medications among those who opted to stop medications $(\mathrm{N}=152)$.

\begin{tabular}{ll}
\hline Reasons for stopping medications & $\%(\mathrm{~N})$ \\
\hline Medical Stores closed & 30.3 \\
Had doubt about the dose of medicines and had other medical & $(46)$ \\
condition & 18.4 \\
Had financial difficulties since I did not have a job & $(28)$ \\
Not venturing out due to fear of contracting COVID-19 & 17.8 \\
Mental stress & $(27)$ \\
Not answered & $9.9(15)$ \\
My sugar level being normal and inability to consult a doctor & $7.2(11)$ \\
Medicines were not available & $5.9(9)$ \\
Couldn't consult doctor & $4.6(7)$ \\
& $3.3(5)$ \\
& $2.6(4)$ \\
\hline
\end{tabular}

$\%$ - Percentage; N - Frequency.

Asian sub-groups, support from family serves to buffer the deleterious effects of stress on glucose levels. ${ }^{19}$ Though not directly associated, family members are key sources in providing both instrumental and emotional support in self-management of T2D. ${ }^{20}$ Perhaps this explains the significant observation that majority of T2D patients who felt good by spending time with family were not under stress.

In the present study, we also observed that about $30 \%$ of T2D patients had irregular sleep pattern and significant proportion of patients with deficient sleep were under stress suggesting a link between T2D, stress and sleeping patterns. Sleep disturbances are common among individuals with diabetes and often report higher rates of insomnia. ${ }^{21}$ In addition, sleep curtailment due to lifestyle choices are linked with higher risk of T2D. ${ }^{22}$ Stress can decrease or increase intake of foods typically considered to promote good health. We observed that those under stress had a significant change in their dietary patterns which was similar to a study reported in literature. ${ }^{23}$ Study participants in the present study who were engaged in a hobby during lockdown were significantly free from stress. It is known that individuals engaged in enjoyable leisure activities like a hobby have better psychological functioning and provide relief from concerns that normally occupy the mind. ${ }^{24,25}$

We also made an attempt to determine the knowledge and awareness regarding effect of COVID-19 and preventive measures that patients with T2D were implementing. Majority of patients were aware of the effect of COVID-19 on other co-morbidities and were taking full precautions as a preventive measures.

However, the crux of the present study was to identify steps taken by patients with T2D who were not able to consult their treating physician $(\mathrm{N}=1171)$ and their relationship with patients blood sugar levels. It was surprising that about $2 \%$ increased their dosage and $5.6 \%$ reduced their dosage of anti-diabetic medications when they could not consult their treating physicians. Cross-tabulating with blood sugar level revealed that this minor fluctuation in dosage was observed significantly more among those T2D patients with uncontrolled blood sugar level. Regular exercise has shown to improve blood sugar level among patients, ${ }^{26}$ thereby inversely supporting our finding that a significant proportion of T2D patients with uncontrolled blood sugar levels were not exercising. In addition, those with controlled blood sugar level not under stress were exercising regularly and indulged in a hobby during the lockdown.

\subsection{Strength of the study}

Restrictions implemented due to COVID-19 represented a unique, window of opportunity to evaluate the effects of home-confinement in a free-living world. It could be anticipated that this situation might have had deleterious impact on diabetes related complications. Nevertheless, this hypothesized impact may have been buffered by other consequences of lockdown such as more regular lifestyle (e.g., more homemade food), increased time to work on their daily challenges of self-care and perhaps a slowdown in their otherwise frenzied life. In addition, a change in the type and length of exercise, indulging in enjoyable leisure activity might be one of the factors.

\subsection{Limitations}

It is important to mention about limitations of the study. 1) Given the cross - sectional study design, we cannot draw any conclusions regarding the causality, 2) we did not make an attempt to determine if physicians utilized tele-consultation [as recommended by Government of India $]^{27}$ as a means to obtain guidance from their treating physicians, 3) we did not utilize any instrument to identify study participants who 
Table 3

Relationship between stress, perceived difficulties, exercise, dietary and sleep pattern during lockdown among study participants.

\begin{tabular}{|c|c|c|c|c|}
\hline \multirow[b]{2}{*}{$\begin{array}{l}\text { Perspective difficulties/state } \\
\text { during lockdown }\end{array}$} & \multicolumn{2}{|c|}{$\begin{array}{l}\text { Were you under stress } \\
\text { during lockdown }\end{array}$} & \multirow{2}{*}{$\begin{array}{l}\chi^{2} \\
\text { value } \\
214.8\end{array}$} & \multirow{2}{*}{$\begin{array}{l}P \text { value } \\
\mathrm{P}= \\
0.0001 *\end{array}$} \\
\hline & $\begin{array}{l}\text { Yes } \\
\%(N)\end{array}$ & $\begin{array}{l}\text { No } \\
\%(N)\end{array}$ & & \\
\hline $\begin{array}{l}\text { Physical, mental, financial } \\
\text { Kind of difficult } \\
\text { Good to spend time with } \\
\text { family }\end{array}$ & $\begin{array}{l}26.05 \\
(99) \\
37.37 \\
(142) \\
36.58 \\
(139)\end{array}$ & $\begin{array}{l}3.31(34) \\
26.32 \\
(270) \\
70.37 \\
(720)\end{array}$ & & \\
\hline $\begin{array}{l}\text { Total } \\
\text { Change in dietary pattern }\end{array}$ & 380 & 1026 & & \\
\hline Yes & $\begin{array}{l}23.95 \\
(91)\end{array}$ & $\begin{array}{l}11.4 \\
(117)\end{array}$ & 34.6 & $\begin{array}{l}P= \\
0.0001 *\end{array}$ \\
\hline No & $\begin{array}{l}76.05 \\
(289)\end{array}$ & $\begin{array}{l}88.6 \\
(909)\end{array}$ & & \\
\hline Total & 380 & 1026 & & \\
\hline $\begin{array}{l}\text { Spend time during lockdown } \\
\text { Slept more }\end{array}$ & $\begin{array}{l}17.89 \\
(68)\end{array}$ & $\begin{array}{l}10.72 \\
(110)\end{array}$ & & \\
\hline $\begin{array}{l}\text { Busy with hobby } \\
\text { Excessive TV } \\
\text { Could not spend time at home }\end{array}$ & $\begin{array}{l}46.84 \\
(178) \\
25.53 \\
(97) \\
9.74(37)\end{array}$ & $\begin{array}{l}55.46 \\
(569) \\
23.39 \\
(240) \\
10.43 \\
(107)\end{array}$ & 15.8 & $\begin{array}{l}P= \\
0.0001 *\end{array}$ \\
\hline $\begin{array}{l}\text { Total } \\
\text { Changes in Sleeping pattern }\end{array}$ & 380 & 1026 & & \\
\hline No Changes & $\begin{array}{l}50.26 \\
(191)\end{array}$ & $\begin{array}{l}76.2 \\
(782)\end{array}$ & & \\
\hline Sleeping Less & $\begin{array}{l}42.11 \\
(160)\end{array}$ & $\begin{array}{l}13.74 \\
(141)\end{array}$ & 132.9 & $\begin{array}{l}P= \\
0.0001 *\end{array}$ \\
\hline Sleeping more & $7.63(29)$ & $\begin{array}{l}10.04 \\
(103)\end{array}$ & & \\
\hline $\begin{array}{l}\text { Total } \\
\text { Difficulty in procuring drugs }\end{array}$ & 380 & 1026 & & \\
\hline Yes & $\begin{array}{l}26.05 \\
(99)\end{array}$ & $\begin{array}{l}16.08 \\
(165)\end{array}$ & 18.1 & $\begin{array}{l}P= \\
0.0001 *\end{array}$ \\
\hline No & $\begin{array}{l}73.95 \\
(281)\end{array}$ & $\begin{array}{l}83.92 \\
(861)\end{array}$ & & \\
\hline $\begin{array}{l}\text { Total } \\
\text { Level of blood sugar }\end{array}$ & 380 & 1026 & & \\
\hline $\begin{array}{l}\text { Controlled } \\
\text { Un-controlled }\end{array}$ & $\begin{array}{l}52.99 \\
(133) \\
47.01 \\
(118)\end{array}$ & $\begin{array}{l}63.24 \\
(461) \\
36.76 \\
(268)\end{array}$ & 8.2 & $\begin{array}{l}\mathrm{P}= \\
0.0001\end{array}$ \\
\hline Total & 251 & 729 & & \\
\hline
\end{tabular}

*statistically significant at $P<0.01$ using Chi-square $\left(\chi^{2}\right)$ test, Level of significance at $P<0.05$.

$\%$ - Percentage; N - Frequency.

reported themselves as being under stress, and 4) a certain degree of social desirability bias can be expected in responses by study participants.

\subsection{Recommendations}

In the event of a similar lockdown in the future, it is important to realize necessary measures of diabetes care to prevent further complications.

1. Lifestyle modifications (at home physical activity/exercise regularly, regular healthy diet, engaging yourself with a leisure hobby)

2. Try to practice SMBG.

3. Establish contact with your local pharmacy and placing orders well in advance (for Anti-diabetic drugs or glucometer/strips)

4. Tele-consultations with your treating physicians for guidance and drug compliance.

5. Patients should feel free to discuss their psychological issues with their physicians.
Table 4

Determining association between controlled/uncontrolled sugar levels and other variables.

\begin{tabular}{|c|c|c|c|c|}
\hline & \multicolumn{2}{|l|}{ Sugar levels } & \multirow[b]{2}{*}{$\begin{array}{l}\chi^{2} \\
\text { Value }\end{array}$} & \multirow[b]{2}{*}{$P$ Value } \\
\hline & $\begin{array}{l}\text { Controlled } \\
\%(\mathrm{~N})\end{array}$ & $\begin{array}{l}\text { Uncontrolled } \\
\%(\mathrm{~N})\end{array}$ & & \\
\hline \multicolumn{5}{|l|}{ Exercise } \\
\hline Yes & $\begin{array}{l}58.75 \\
(349)\end{array}$ & 48.96 (189) & 9.1 & $P=0.001 *$ \\
\hline No & $\begin{array}{l}41.25 \\
(245)\end{array}$ & $51.04(197)$ & & \\
\hline \multicolumn{5}{|l|}{ Sleeping Pattern } \\
\hline No Change & 71.72 & $67.62(261)$ & 6.6 & $P=0.001^{*}$ \\
\hline Less sleep & $(426)$ & $25.65(99)$ & & \\
\hline More sleep & $\begin{array}{l}19.19 \\
(114) \\
9.09(54)\end{array}$ & $6.74(26)$ & & \\
\hline Total & 594 & 386 & & \\
\hline \multicolumn{5}{|c|}{ If, did not consult doctor, then } \\
\hline Increased Dosage & $3.43(16)$ & 6.07 (19) & 10 & $P=0.001 *$ \\
\hline Decreased Dosage & $1.07(5)$ & $2.88(19)$ & & \\
\hline Stopped Medication & $5.15(24)$ & $7.67(24)$ & & \\
\hline Took as prescribed & 88.63 & $82.43(258)$ & & \\
\hline Others/NA & $(413)$ & $0.96(3)$ & & \\
\hline & $1.72(8)$ & & & \\
\hline Total & 466 & 313 & & \\
\hline \multicolumn{5}{|c|}{ Spend time during lockdown } \\
\hline Slept more & $9.93(59)$ & $14.25(55)$ & 14 & $\mathrm{P}=$ \\
\hline Busy with hobby & 60.44 & $48.96(189)$ & & $0.0001 *$ \\
\hline Excessive TV & $(359)$ & $26.42(102)$ & & \\
\hline Could not spend time at & 19.7 (117) & $10.36(40)$ & & \\
\hline home & $9.93(59)$ & & & \\
\hline Total & 594 & 386 & & \\
\hline
\end{tabular}

*statistically significant at $\mathrm{P}<0.01$ using Chi-square $\left(\chi^{2}\right)$ test, Level of significance at $\mathrm{P}<0.05$.

$\%$ - Percentage; N - Frequency.

6. Make an attempt to spend quality time with their near and dear ones.

\section{Conclusion}

COVID-19 has triggered a global concern particularly in relation to diabetes which has evidenced poorer outcomes. With a certain degree of uncertainty during lockdown, it was found that majority of patients with T2D were not able to consult their physicians. However, a large proportion of patients were following self-care practices necessary for the management of Diabetes.

\section{Source of support}

None.

\section{Author contribution}

All authors contributed to subject recruitment, data collection, review and discussion of the manuscript.

\section{Funding}

None.

\section{Data availability}

The data sets for the present study are available with the corresponding author and will be made available on reasonable request.

\section{Ethical approval and informed verbal consent}

The study was conducted in accordance with the Declaration of 
Helsinki. Informed verbal consent was obtained after explaining the nature of study.

\section{Declaration of competing interest}

The authors declare that there is no conflict of Interest.

\section{Acknowledgement}

The authors would like to thank the participants who consented to be a part of the study. The authors also would like to thank Medeva. io for bio-statistical analysis and interpretation of data.

\section{References}

1 Jordan RE. Covid-19: risk factors for severe disease and death. A long list is emerging from largely unadjusted analyses, with age near the top. BMJ. 2020;368:m1198. https://doi.org/10.1136/bmj.m1198.

2 Diabetes Health topic. World health organization. https://www.who.int/health -topics/diabetes\#tab=tab 1. Last accessed 28th July 2020.

3 World Diabetes Day 2019. India. World health organization. https://www.who.int /india/events/world-diabetes-day. Last accessed 28th July 2020.

4 Saeedia P, Petersohna I, Salpeaa P, et al. Global and regional diabetes prevalence estimatesfor 2019 and projections for 2030 and 2045: results from the international diabetes federation diabetes atlas, 9thedition. Diabetes Research and Clinical Practice157; 2019. https://doi.org/10.1016/j.diabres.2019.107843.

5 Apicella M, Campopiano MC, Mantuano M, Mazoni L, Coppelli A, DelPrato F. COVID 19 in people with diabetes: understanding the reasons for worse outcomes. Lancet. 2020. https://doi.org/10.1016/S2213-8587(20)30238-2. Published online July 17, 2020.

6 Petrilli CM, Jones SA, Yang J, et al. Factors associated with hospitalization and critical illness among 4,103 patients with COVID-19 disease in New York City. BMJ. 2020. https://doi.org/10.1101/2020.04.08.32444366. published online April 11.

7 Roncon L, Zuin M, Rigatelli G, Zuliani G. Diabetic patients with COVID-19 infection are at higher risk of ICU admission and poor short-term outcome. J Clin Virol. 2020; 127:104354.

8 Barron E, Bakhai C, Kar P, et al. Type 1 and type 2 diabetes and COVID-19 related mortality in England: a whole population study. https://www.england.nhs.uk/ wp-content/uploads/2020/05/valabhji-COVID-19-and-diabetes-paper-1.pdf. Last accessed August 4th, 2020.

9 Cariou B, Hadjadj S, Wargny M, et al. Phenotypic characteristics and prognosis of inpatients with COVID-19 and diabetes: the CORONADO study. Diabetologia. 2020. https://doi.org/10.1007/s00125-020-05180-x. published online May 29.
10 Characteristics of Sars-CoV-2 patients dying in Italy. Analysis of deaths. News SARSCoV-2. Epidemiology for public health. EpiCentro. https://www.epicentro.iss.it. [Last updated July 22nd, 2020; Last accessed August 4th 2020].

11 World Medical Association. Declaration of Helsinki. Ethical Principles for Medical Research Involving Human Subjects. Seoul: 59th WMA General Assembly; 2008.

12 Aade. Aade7. Self-care behaviors. Diabetes Educat. 2008;34:445-449.

13 Banerjee M, Chakraborty S, Pal R. Diabetes self-management amid COVID-19 pandemic. Diabetes \& metabolic syndrome. Clin Res Rev. 2020;14:351-354. https:// doi.org/10.1016/j.dsx.2020.04.013.

14 Nachimuthu S, Vijayalakshmi R, Sudha M, Viswanathan V. Coping with diabetes during the COVID-19 lockdown in India: results of an online pilot survey. Diabetes \& Metabolic Syndrome: Clin Res Rev. 2020;14:572-582. https://doi.org/10.1016/j. dsx.2020.04.053.

15 Selvaraj K, Ramaswamy G, Radhakrishnan S, Thekkur P, Chinnakali P, Roy G. Selfcare practices among diabetes patients registered in a chronic disease clinic in Puducherry, South India. J Soc Health Diabetes. 2016;4:25-29.

16 Gopichandran V, Lyndon S, Angel MK, et al. Diabetes self-care activities: a community-based survey in urban southern India. Natl Med J India. 2012;25:14-17.

17 Polonsky WH, Hajos TR, Dain MP, Snoek FJ. Are patients with type 2 diabetes reluctant to start insulin therapy? An examination of the scope and underpinnings of psychological insulin resistance in a large, international population. Curr Med Res Opin. 2011;27:1169-1174.

18 Luyckx K, Seiffge-Krenke I, Hampson SE. Glycemic control, coping, and internalizing and externalizing symptoms in adolescents with type 1 diabetes: a cross-lagged longitudinal approach. Diabetes Care. 2010;33:1424-1429.

19 Griffith LS, Field BJ, Lustman PJ. Life stress and social support in diabetes: association with glycemic control. Int J Psychiatr Med. 1990;20:365-372.

20 Baig AA, Benitez A, Quinn MT, Burnet DL. Family interventions to improve diabetes outcomes for adults. Ann N Y Acad Sci. 2015;1353:89-112. https://doi.org/10.1111/ nyas. 12844 .

21 Skomro RP, Ludwig S, Salamon E, Kryger MH. Sleep complaints and restless legs syndrome in adult type 2 diabetics. Sleep Med. 2001;2:417-422.

22 American Diabetes Association. Comprehensive medical evaluation and assessment of comorbidities. Diabetes Care. 2017;40(Suppl 1):S25-S32.

23 Laugero KD, Falcon LM, Tucker KL. Relationship between perceived stress and dietary and activity patterns in older adults participating in the Boston Puerto Rican Health Study. Appetite. 2011;56(1):194-204. https://doi.org/10.1016/j. appet.2010.11.001.

24 Pressman SD, Matthews KA, Cohen S, et al. Association of enjoyable leisure activities with psychological and physical well-being. Psychosom Med. 2009;71(7):725-732. https://doi.org/10.1097/PSY.0b013e3181ad7978.

25 Kaplan S. The restorative benefits of nature: toward an integrative framework. J Environ Psychol. 1995;15:169-182.

26 Joshi SR. Diabetes care in India. Annals of Global Health. 2015;81(6):830-838.

27 Telemedicine Practice Guidelines. Board of governors. Ministry of health and family welfare. http://www.mohfw.gov.in/pdf/Telemedicine.pdf. Last accessed on 25 August 2020 